\title{
APPENDIX 2
}

\section{Indian volunteer railway units, 1869-1901}

\begin{tabular}{|c|c|c|}
\hline $\begin{array}{l}\text { Year of } \\
\text { formation }\end{array}$ & Name & Comments \\
\hline 1869 & $\begin{array}{l}\text { East Indian Railway } \\
\text { Volunteer Rifle Corps }\end{array}$ & $\begin{array}{l}\text { On } 20 \text { May 1890, it } \\
\text { absorbed Sibpore College } \\
\text { Volunteer Rifle Corps }\end{array}$ \\
\hline 1873 & $\begin{array}{l}\text { Eastern Bengal State } \\
\text { Railway Volunteer } \\
\text { Rifle Corps }\end{array}$ & \\
\hline 1879 & $\begin{array}{l}\text { Northern Bengal State } \\
\text { Railway Volunteer } \\
\text { Rifle Corps }\end{array}$ & $\begin{array}{l}\text { In } 1882 \text {, the two Bengal } \\
\text { Railway corps were } \\
\text { amalgamated as the } \\
\text { Eastern Bengal Railway } \\
\text { Volunteer Rifle Corps }\end{array}$ \\
\hline 1875 & $\begin{array}{l}\text { Great Indian Peninsula } \\
\text { Railway Volunteer } \\
\text { Corps }\end{array}$ & $\begin{array}{l}\text { In } 1902 \text {, it was absorbed as } \\
\text { the } 2^{\text {nd }} \text { Battalion, Midland } \\
\text { Railway Volunteer Corps }\end{array}$ \\
\hline 1877 & $\begin{array}{l}\text { Bombay, Baroda and } \\
\text { Central India Railway } \\
\text { Volunteer Corps }\end{array}$ & $\begin{array}{l}\text { In } 1886 \text {, it absorbed the } \\
\text { Ghadeshi Volunteer Rifle } \\
\text { Corps, and in } 1887 \text { it was } \\
\text { amalgamated with the } \\
\text { Rajputana-Malva Volunteer } \\
\text { Rifle Corps }\end{array}$ \\
\hline 1879 & $\begin{array}{l}\text { Tirhut State Railway } \\
\text { Volunteer Rifle Corps }\end{array}$ & $\begin{array}{l}\text { On } 17 \text { June } 1892 \text {, it } \\
\text { absorbed the Ghazipur } \\
\text { Volunteer Rifle Corps }\end{array}$ \\
\hline 1884 & $\begin{array}{l}\text { Southern Indian } \\
\text { Railways Volunteer } \\
\text { Rifle Corps }\end{array}$ & \\
\hline 1885 & $\begin{array}{l}\text { Madras Railway } \\
\text { Volunteer Corps }\end{array}$ & \\
\hline
\end{tabular}


APPENDIX 2

$\begin{array}{lll}1886 & \begin{array}{l}\text { Sind, Punjab and Indus } \\ \text { Valley Railways Rifle } \\ \text { Corps }\end{array} & \begin{array}{l}\text { In 1888, the name was } \\ \text { changed to } 3^{\text {rd }} \text { Punjab } \\ \text { (North-Western Railway) } \\ \text { Volunteer Rifle Corps, and } \\ \text { in 1892, to North-Western } \\ \text { Railway Volunteer Rifles }\end{array} \\ 1886 & \begin{array}{l}\text { In1898, it absorbed the } \\ \text { Bellary Volunteer Rifle } \\ \text { Railway Rifle Corps }\end{array} & \begin{array}{l}\text { Corps } \\ \text { In 1898, it absorbed the }\end{array} \\ 1888 & \begin{array}{l}\text { Bengal Nagpur Railway } \\ \text { Volunteer Rifle Corps }\end{array} & \begin{array}{l}\text { Orissa Volunteer Rifles, and } \\ \text { in 1903, it was organized in } \\ \text { two battalions }\end{array} \\ 1901 & \begin{array}{l}\text { Midland Railway } \\ \text { Volunteer Corps } \\ \text { Assam Bengal Railway } \\ \text { Volunteer Rifles }\end{array} & \end{array}$

Adapted from Gaylor, Sons of John Company, pp. 39-43; Roy, 'India' in Beckett (ed.), Citizen Soldiers, pp. 115-16. 